\title{
The indirect effect of body image on distress in women with breast cancer undergoing chemotherapy
}

\section{BACKGROUND}

This study assessed the indirect effect of body image in the relationship between illness duration, optimism, coping strategies and psychological distress as well as the moderator role of being or not submitted to surgery and type of surgery, in women with breast cancer undergoing chemotherapy.

\section{PARTICIPANTS AND PROCEDURE}

This cross-sectional study included eighty-seven women with breast cancer undergoing chemotherapy, who answered instruments that assessed sociodemographic and clinical issues, optimism, coping, concerns with body image and psychological distress. Bayesian statistics were performed to test the indirect effect model that included also the moderator effects.

\section{RESULTS}

Lower optimism, lower use of humor, and higher denial and illness duration predicted lower body image and high- er distress. Longer illness duration was associated with higher distress. Body image had an indirect effect in the relationship between optimism and distress; between denial coping and distress; between humor coping and distress and between illness duration and distress. Being submitted to surgery but not the type of surgery was a moderator in the indirect effect model.

\section{CONCLUSIONS}

Body image is critical to psychological distress. Future interventions for women with breast cancer should consider body image as a target, in order to promote adaptive coping strategies specially when women have had surgery.

\section{KEY WORDS}

body image; breast neoplasms; adaptation psychological; optimism; psychological distress

ORganization - 1: School of Psychology, University of Minho, Braga, Portugal · 2: Institute of Social Sciences,

University of Minho, Braga, Portugal

AUthors' COntributions - A: Study design - B: Data collection - C: Statistical analysis - D: Data interpretation .

E: Manuscript preparation · F: Literature search · G: Funds collection

Corresponding AUthor - Prof. M. Graça Pereira, School of Psychology, University of Minho, Campus de Gualtar,

4710-057 Braga, Portugal, e-mail: gracep@psi.uminho.pt

to Cite this article - Pereira, M. G., Ribeiro, C., Ferreira, G., Machado, J. C., \& Leite, Â. (2022). The indirect effect

of body image on distress in women with breast cancer undergoing chemotherapy. Health Psychology Report, 10(1),

47-57. https://doi.org/10.5114/hpr.2022.113381 


\section{BACKGROUND}

Breast cancer is the cancer with the highest incidence in women worldwide (25.1\%) and in Portugal (29.4\%) (Ferlay et al., 2014), accounting for 571,000 deaths in 2015 (WHO, 2019). Breast cancer occupies the top spot in cancer mortality in women worldwide (14.7\%) and in Portugal (16.0\%) (Ferlay et al., 2014).

The diagnosis and treatment of breast cancer has a negative impact on women's physical and psycho-
M. Graça Pereira, Catarina Ribeiro, Gabriela Ferreira, José C. Machado, Ângela Leite logical well-being, since it may trigger fears about death, changes in body image, femininity, and motherhood (Reich et al., 2007). Cancer treatment includes surgery and/or adjuvant therapies (e.g. chemotherapy, radiotherapy), with secondary effects such as weight gain, loss of hair and disfigurement, causing significant changes in women's body image (Dua et al., 2015). In addition, breast cancer surgery may include the removal of the entire breast (mastectomy) or only the tumor (conserving surgery) (American Cancer Society, 2019). Al-Ghazal et al. (2000) and Hopwood and Hopwood (2019) reported that when the surgery was more drastic and invasive, women's psychological well-being was more threatened, although Chow and colleagues (2015) found no differences. After 5 years of surgery, breast-conserving surgery has been associated with better body image and higher psychosocial well-being and quality of life than mastectomy (Chow et al., 2015). Body image is also dependent on type and time after surgery (better in breast-conserving therapy than in modified radical mastectomy and improving over time) as well as relationship quality (better in couples with high quality and shorter duration of their relationship) (Kowalczyk et al., 2019).

The literature has shown that body image also plays a mediator role regarding self-esteem (You et al., 2016). In fact, body embarrassment predicted lower self-esteem (Grift et al., 2018) and body image acceptance mediated the relationship between body image and self-esteem (Brandt-Salmeri \& PrzybyłaBasista, 2019). In women with lymphedema secondary to breast cancer, body image dissatisfaction mediated the relationship between pain and depressive symptoms (higher levels of pain led to higher states of body image dissatisfaction, which led to greater depressive symptoms); body image dissatisfaction also mediated the relationship between body integrity beliefs and depressive symptoms (greater body integrity beliefs led to higher dissatisfaction with one's body and subsequently to greater depressive symptoms; Teo et al., 2015). Fang et al. (2014) found an indirect relationship of body consciousness with depression through the mediating role of body image discomfort, i.e., women with higher objectified body consciousness reported more cancer-related body image discomfort, which was related to greater depression, and the degree of the mediation relationship was different across surgery types. Body image flex- ibility was found to be a mediating variable between negative body image and maladaptive behavioral outcomes (Rogers et al., 2018).

Several factors have been identified and studied as resilience sources in women with breast cancer (Carver, 2015), such as optimism, which has a positive impact on psychological well-being and was associated with lower levels of psychological distress (Carver, 2015), higher emotional well-being (Li et al., 2019), and better quality of life (Ristevska-Dimitrovska et al., 2015). Optimism has also been positively associated with active coping strategies, planning, acceptance of the real situation and humor coping and negatively with avoidance coping strategies such as denial and behavioral disengagement, in women with breast cancer (Carver, 2015). Also, the more optimistic women adopted the fighting spirit strategy while the more pessimistic ones used the hopeless/helpless strategy (Casellas-Grau et al., 2016).

Active coping strategies, such as positive cognitive restructuring and active engagement, have been associated with lower distress (Carver, 2015), higher psychological well-being, and better quality of life (Brunault et al., 2015), while poor/avoidance coping strategies, such as denial, disengagement, anxious preoccupation, fatalism, wishful thinking, and helplessness/hopelessness, were associated with higher distress, in women with breast cancer (Brunault et al., 2015).

Psychological distress was found to be predicted by body image (Griffiths et al., 2016), by optimism (Brandão et al., 2016), by denial coping (Di Mattei et al., 2016), by humor coping (Feudis et al., 2015) and by illness duration (Millar et al., 2005). However, the relationship between body image, coping strategies, optimism, and psychological distress, taking into consideration illness duration, surgery, and the type of surgery, needs further clarification, in women with no breast reconstruction. To fill this gap, this study evaluated the meditating role of body image in the relationship between coping strategies, optimism, illness duration, and psychological distress, considering whether patients were submitted to surgery or not and the type of surgery, as well. The hypotheses were: (1) body image will show an indirect effect in the relationship between: a) distress and coping strategies/ optimism and b) illness duration and distress; (2) having or not surgery and type of surgery will moderate the indirect effect model.

\section{PARTICIPANTS AND PROCEDURE}

\section{PARTICIPANTS}

A convenience sample of 87 women diagnosed with breast cancer undergoing chemotherapy treatment at the Oncology Service of a major public hospital, in 
the north of Portugal participated in the study. Data collection took approximately seven months. The inclusion criteria in the study were the following: 1) age greater than 18 years; 2) a diagnosis of breast cancer; and 3) being in chemotherapy treatment. The presence of severe psychological disorders (e.g. psychosis) in the patient's medical records was an exclusion criterion. The study was approved by the Ethics Committee of the Hospital $(\mathrm{HB} / 2017)$ where data collection took place and was performed in accordance with the ethical standards of the Declaration of Helsinki and its later amendments. Patients undergoing chemotherapy were invited to participate by their oncologist and later approached by the researcher. Participation was voluntary and patients were informed about the aims of the study and the confidentiality of the data, signing an informed consent form for this purpose.

\section{MEASURES}

Revised Life Orientation Test (LOT-R; Scheier et al., 1994). This instrument assesses the levels of optimism and its influence in the processes of adaptation to an illness. It consists of 10 items, in which only six assess optimism (e.g., "At difficult times I usually expect the best"; "In general, I hope that more good things happen to me than more bad things") and the remaining items are distractors (e.g., "For me, it's easy to relax"; "I am happy to be with my friends"). Higher results indicate higher levels of optimism. In the original version by Scheier et al. (1994), a Cronbach's $\alpha$ of .84 was found. The Portuguese version (Laranjeira, 2008) showed an $\alpha$ of .78, whereas in the present study it was .71.

Brief COPE (Carver, 1997). This instrument assesses the individual adjustment to stressful situations and was originally composed of 52 items organized in 13 scales. In the adapted Portuguese version (Ribeiro \& Rodrigues, 2004), the questionnaire consists of 28 items, divided into 14 subscales: Active Coping (e.g., "I concentrate my efforts on doing something that allows me to face the situation"), Planning (e.g., "I try to find a strategy that will help me with what I have to do"), Using Instrumental Support (e.g., "I ask for advice and help others to better face the situation"), Using Social and Emotional Support (e.g., "I seek emotional support from someone (family, friends)"), Religion (e.g., "I pray or I meditate"), Positive Reframing ("I look for something positive in everything that is happening"), Self-Blame (e.g., "I criticize myself"), Acceptance (e.g., "I try to accept things as they are happening"), Venting (e.g., "I get bored and express my feelings (emotions)"), Denial (e.g., "I have said to myself: this is not true"), Self-Distraction (e.g., "I take refuge in other activities to be distracted from the situation"), Behavioral Disengagement (e.g., "I give up trying to get what I want"), and Substance Use (e.g.,
"I take refuge in alcohol or other drugs [tablets, etc.] to feel better") and Humor (e.g., "I face the situation by treating it as a game") (Carver, 1997). In the original version $\alpha$ ranged from .50 (venting) to .90 (substance use). In the Portuguese version, Cronbach's $\alpha$ ranged between .55 and .84 (Ribeiro \& Rodrigues, 2004). In the present study, alphas were similar to the original and the Portuguese version, i.e. .61 (self-distraction), .63 (active coping), .87 (denial), .93 (substance use), .69 (emotional support), .82 (use of instrumental support), .73 (behavioral disengagement), .75 (venting), .68 (positive reframing), .62 (planning), .88 (humor), .63 (acceptance), and .86 (religion). All subscales were used in this study except the self-blame subscale due to the alpha (below. 50).

Hospital Anxiety and Depression Scale (HADS; Zigmond \& Snaith, 1983). This instrument assesses psychological distress, including two subscales, anxiety (e.g., "I feel tense or wound up"; "Worrying thoughts go through my mind") and depression (e.g., "I still enjoy the things I used to enjoy"; "I feel as if I am slowed down"), each with seven items. A higher result indicates greater distress. The Portuguese version (PaisRibeiro et al., 2007) presents a Cronbach's $\alpha$ of .94 for the total scale, .91 for the subscale of anxiety and .88 for depression. In this sample, the Cronbach's $\alpha$ for the total scale was .86 , for the anxiety subscale was .82 and for the depression subscale .70 .

Body Image Scale (Hopwood et al., 2001). The instrument assesses the severity of the disease impact on self-image in cancer patients at emotional, behavioral, and cognitive levels. The instrument includes 10 items (e.g., "Have you felt less physically attractive as a result of your disease or treatment?"; "Have you avoided people because of the way you felt about your appearance?"), where higher results indicate greater concerns with body image. In the Portuguese version validated in women with breast cancer, a Cronbach's $\alpha$ of .93 was found (Moreira et al., 2010), while in this sample it was .94 .

\section{DATA ANALYSIS}

The relationships between all variables with body image and optimism were assessed through Pearson correlations. In the path analysis, only the variables that were significantly correlated were introduced. To test the indirect effect model, Bayesian structural equation modeling (SEM) was conducted in AMOS 25.0, due to the small sample size (van de Schoot \& Depaoli, 2014). The Bayesian SEM approach performs maximum likelihood (ML) estimation (Yuan \& Mackinnon, 2009): inference is precise and simpler for multilevel indirect effect analyses, using the Markov Chain Monte Carlo (MCMC) method to extract repeated samples to estimate parameters for each model. The dataset generates a posterior likelihood
Role of body image in women with breast cancer 
M. Graça Pereira, Catarina Ribeiro, Gabriela Ferreira, José C. Machado, Ângela Leite distribution for each parameter estimate. The statistical significance is calculated through the Bayesian credible interval: if it does not overlap zero, the parameter is statistically significant. In this study, model fit was assessed by the posterior predictive $p$ value and the value of a convergence statistic (CS). The posterior predictive $p$ value represents the model's goodness-of-fit and should be interpreted like an SEM fit index: a value closer to 0.5 indicates a better model fit, whereas a value closer to 0 or 1 suggests a poor fit (Song \& Lee, 2006). A CS value of less than 1.002 suggests that the model has converged; a CS value equal to 1.0000 means that the model has a perfect fit. Additionally, the deviance information criterion (DIC) was used, no representing a Bayesian generalization of the Akaike information criterion: models with smaller DIC values should be preferred. The DIC is a combination of the deviance from the model and the penalty for model complexity.

Finally, a two moderated indirect effect model using the Bayesian approach was used to analyze the effects of having undergone (or not) surgery and the type of surgery in the relationship between denial, humor, optimism, illness duration and distress, through body image. Moderated indirect effect analysis is conducted through adding relevant interaction terms into the indirect effect model of interest. In a moderated indirect effect, the pattern of indirect effect changes as a function of the moderator. All statistical analyses were performed using IBM SPSS Statistics 25, and for the structural equation model IBM SPSS Amos 25 was used.

\section{RESULTS}

\section{SAMPLE CHARACTERISTICS}

The sample comprised 87 Portuguese women with breast cancer, aged between 25 and 75 years $(M=51.93$, $S D=12.07)$. Most of the women were married $(78.2 \%)$ and had children (89.7\%). Of the total sample, $48.3 \%$ had a low level of education (up to four years of education) and $51.7 \%$ high school or college education. The mean time of diagnosis was 2.0 years $(S D=2.70)$. Regarding treatment, $61(70.1 \%)$ had surgery. Of those who had surgery, 34 (39.1\%) underwent mastectomy and the remainder (31.0\%) conservative surgery. None of the women who had surgery were submitted to breast reconstruction.

\section{RELATIONSHIP BETWEEN VARIABLES}

Table 1 shows the correlation coefficients between variables. Body image, coping (planning, social and emotional support, religion, acceptance, venting, denial and behavioral disengagement) and illness du- ration were positively associated with psychological distress (outcome variable); other coping dimensions (acceptance and humor), and optimism were negatively associated with psychological distress. Higher optimism was associated with lower levels of distress, less venting, and behavioral disengagement, as well as with greater use of positive reframing, acceptance, and humor. Greater use of denial coping was associated with longer illness duration, and higher distress and concern with body image, and lower optimism. Greater use of humor was associated with a better image, lower distress, and higher optimism. Finally, longer illness duration was associated with higher distress and denial.

\section{PATH ANALYSIS MODEL}

Bayesian SEM was used to test the indirect effect model. Figure 1 shows the final model with a good fit: the model converged with a CS equal to 1.0000 . The goodness-of-fit measures showed that the model was supported by the data, posterior predictive $p=.50$, $\mathrm{DIC}=1418.21$, number of effective parameters $=22.01$. The specific parameter estimates for the model are presented in Table 2; all the parameters were significant, and all the indirect effect estimates were statistically significant because all the $95 \%$ CI did not overlap zero, except in the relationship between humor and body image and between humor and distress. The model showed that lower optimism, higher denial and illness duration predicted greater concerns with body image and higher distress.

\section{INDIRECT EFFECTS}

In order to analyze in which situations body image had an indirect effect in the association between illness duration, optimism, denial, humor and psychological distress, bootstrapping with 4000 samples was used. The results (Table 2) showed that three indirect effects were statistically significant corresponding to the indirect effects between illness duration, optimism, denial and psychological distress.

\section{THE MODERATED INDIRECT EFFECT OF HAVING SURGERY}

For the adjusted model, a moderated indirect effect was tested regarding the two groups: with versus without surgery (Table 3). The results showed that having surgery moderated the relationship between coping denial, coping humor, optimism, and distress, through body image; but not in the relationship between illness duration and distress, through body image (Figure 2). 


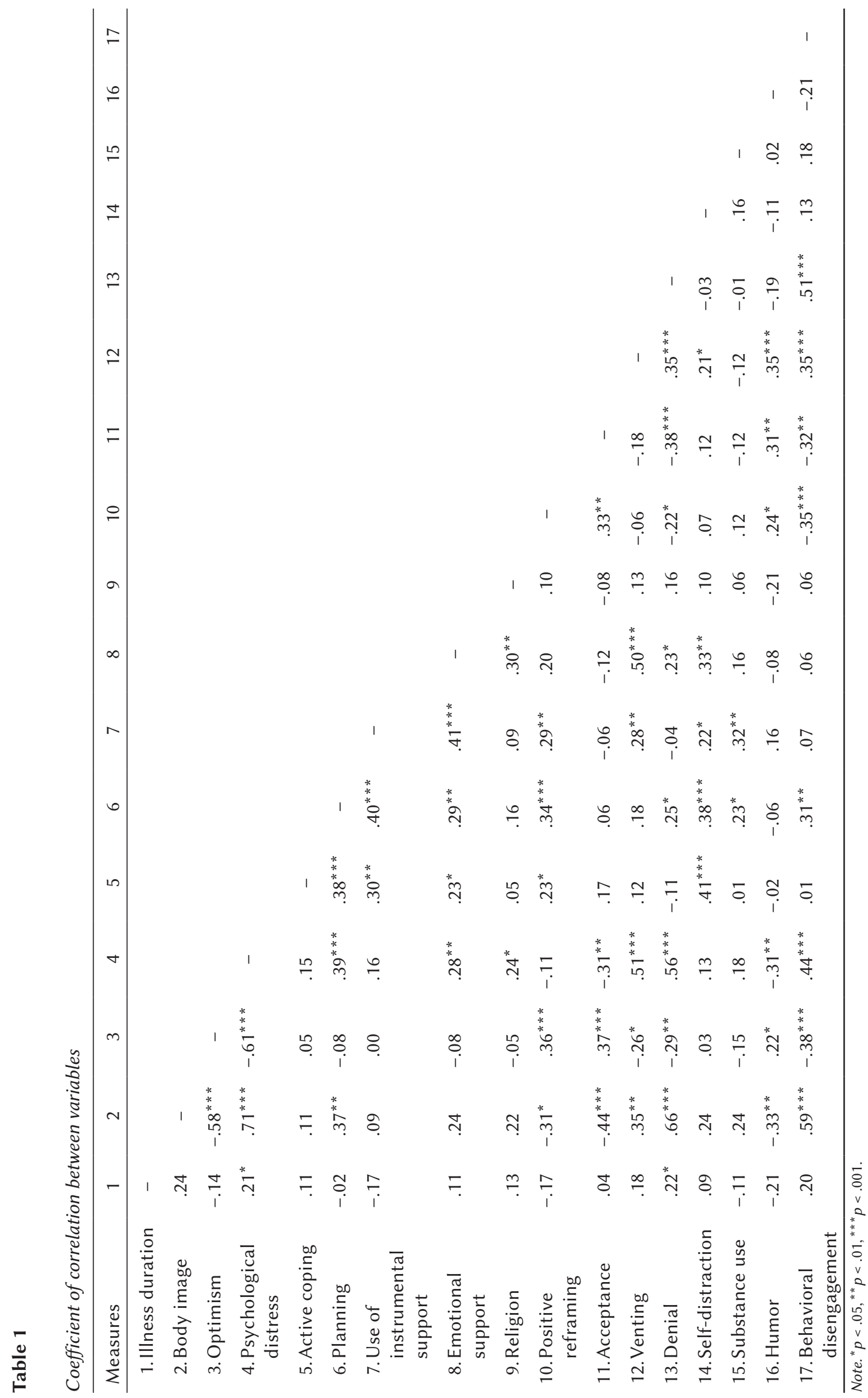

Role of body

image in women

with breast cancer 


\section{Figure 1}

\section{Final SEM model}

M. Graça Pereira, Catarina Ribeiro, Gabriela Ferreira, José C. Machado, Ângela Leite

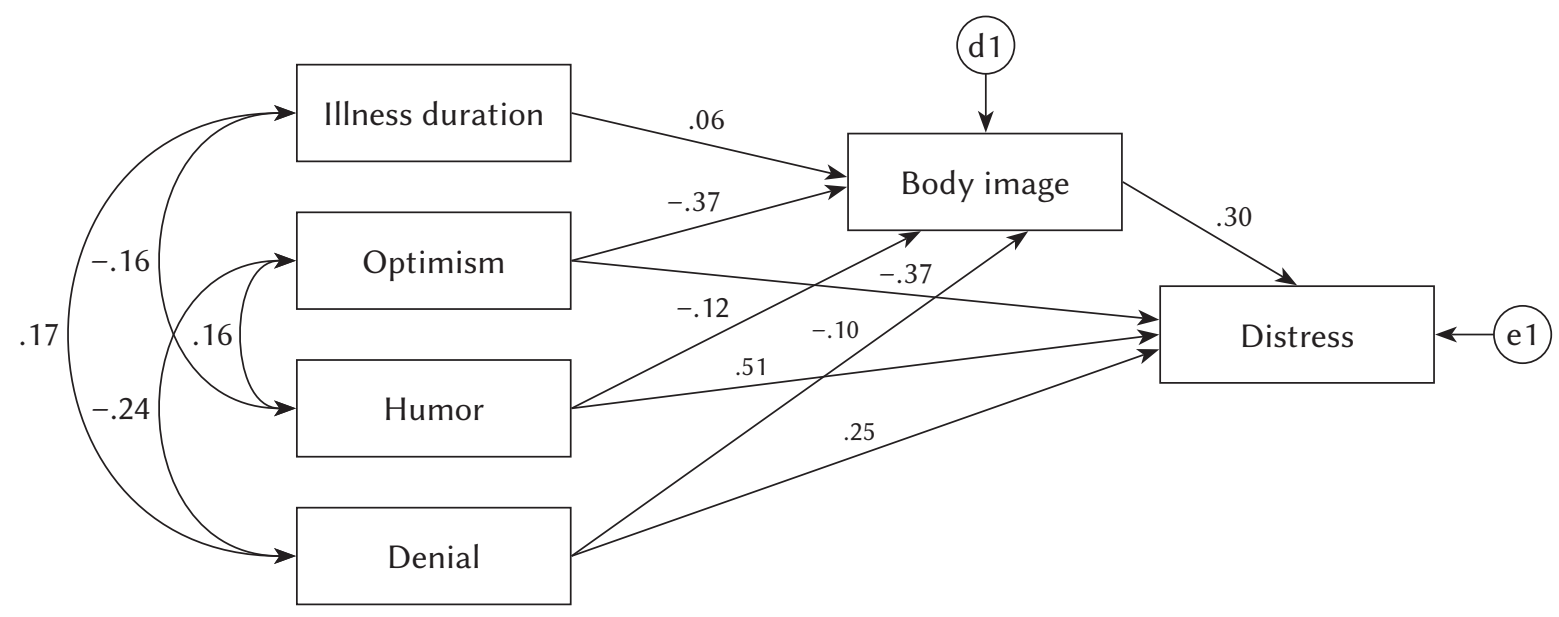

Table 2

Bayesian SEM results: indirect effect analysis

\begin{tabular}{|c|c|c|c|c|c|c|}
\hline & $M$ & $S E$ & $S D$ & $\mathrm{CS}$ & \multicolumn{2}{|c|}{ Credible interval } \\
\hline & & & & & $\begin{array}{l}95 \% \\
\text { Lower } \\
\text { bound }\end{array}$ & $\begin{array}{l}95 \% \\
\text { Upper } \\
\text { bound }\end{array}$ \\
\hline \multicolumn{7}{|l|}{ Regression weights } \\
\hline Body image $\leftarrow$ Optimism & $-0.54^{*}$ & 0.01 & 0.14 & 1.00 & -0.82 & -0.26 \\
\hline Distress $\longleftarrow$ Body image & $0.20^{*}$ & 0.00 & 0.09 & 1.00 & 0.01 & 0.37 \\
\hline Distress $\longleftarrow$ Optimism & $-0.39^{*}$ & 0.00 & 0.09 & 1.00 & -0.57 & -0.21 \\
\hline Distress $\leftarrow$ Denial & $0.75^{*}$ & 0.01 & 0.30 & 1.00 & 0.17 & 1.36 \\
\hline Distress $\leftarrow$ Humor & -0.24 & 0.01 & 0.20 & 1.00 & -0.63 & 0.14 \\
\hline Body image $\leftarrow$ Humor & -0.45 & 0.01 & 0.34 & 1.00 & -1.11 & 0.20 \\
\hline Body image $\leftarrow$ Denial & $2.20^{*}$ & 0.01 & 0.39 & 1.00 & 1.45 & 2.98 \\
\hline \multirow[t]{2}{*}{ Path } & \multirow{2}{*}{$\begin{array}{l}\text { Posterior } \\
\qquad M\end{array}$} & \multirow[t]{2}{*}{$S D$} & \multicolumn{2}{|c|}{ Credible interval } & \multirow{2}{*}{\multicolumn{2}{|c|}{ Conclusion }} \\
\hline & & & $\begin{array}{l}95 \% \\
\text { Lower } \\
\text { bound }\end{array}$ & $\begin{array}{l}95 \% \\
\text { Upper } \\
\text { bound }\end{array}$ & & \\
\hline \multicolumn{7}{|l|}{ Indirect effects } \\
\hline $\begin{array}{l}\text { Distress } \longleftarrow \text { Body image } \\
\leftarrow \text { Illness duration }\end{array}$ & 0.02 & 0.01 & 0.00 & 0.03 & \multicolumn{2}{|c|}{$\begin{array}{l}\text { Positive and } \\
\text { significant }\end{array}$} \\
\hline $\begin{array}{l}\text { Distress } \longleftarrow \text { Body image } \\
\longleftarrow \text { Optimism }\end{array}$ & -0.10 & 0.05 & -0.22 & -0.01 & \multicolumn{2}{|c|}{$\begin{array}{l}\text { Negative and } \\
\text { significant }\end{array}$} \\
\hline $\begin{array}{l}\text { Distress } \longleftarrow \text { Body image } \\
\leftarrow \text { Humor }\end{array}$ & -0.04 & 0.07 & -0.11 & 0.02 & \multicolumn{2}{|c|}{ Not significant } \\
\hline $\begin{array}{l}\text { Distress } \longleftarrow \text { Body image } \\
\longleftarrow \text { Denial }\end{array}$ & 0.14 & 0.01 & 0.01 & 0.29 & \multicolumn{2}{|c|}{$\begin{array}{l}\text { Positive and } \\
\text { significant }\end{array}$} \\
\hline
\end{tabular}

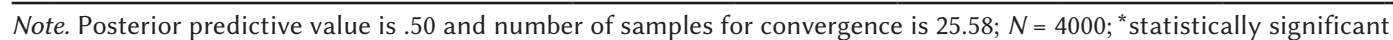
(i.e., the 95\% credible interval does not include zero); SE - standard error; CS - convergence statistic. 
Table 3

Bayesian moderated indirect effect analysis: having surgery or not

\begin{tabular}{|c|c|c|c|c|c|}
\hline $\begin{array}{l}\text { Path } \\
\text { Indirect effects }\end{array}$ & $\begin{array}{c}\text { Posterior } \\
M\end{array}$ & $S D$ & $\begin{array}{l}95 \% \\
\text { Lower } \\
\text { bound }\end{array}$ & $\begin{array}{l}95 \% \\
\text { Upper } \\
\text { bound }\end{array}$ & Conclusion \\
\hline
\end{tabular}

The effect of undergoing or not undergoing surgery in the relationship between denial and distress, indirect effect by body image

\begin{tabular}{|c|c|c|c|c|c|}
\hline Distress $\longleftarrow$ Body image $\longleftarrow$ Denial & $0.11^{*}$ & 0.03 & 0.07 & 0.17 & Positive and significant \\
\hline $\begin{array}{l}\text { Distress } \leftarrow \text { Body image } \leftarrow \text { Surgery } \\
\times \text { Denial }\end{array}$ & $0.21^{*}$ & 0.08 & 0.06 & 0.38 & Positive and significant \\
\hline Distress $\longleftarrow$ Body image $\leftarrow$ Surgery & $0.03^{*}$ & 0.01 & 0.01 & 0.04 & Positive and significant \\
\hline
\end{tabular}

The effect of undergoing or not undergoing surgery in the relationship between humor and distress, indirect effect by body image

\begin{tabular}{|c|c|c|c|c|c|}
\hline Distress $\longleftarrow$ Body image $\longleftarrow$ Humor & $0.18^{*}$ & 0.02 & 0.14 & 0.23 & Positive and significant \\
\hline $\begin{array}{l}\text { Distress } \leftarrow \text { Body image } \leftarrow \text { Surgery } \\
\times \text { Humor }\end{array}$ & $-0.55^{*}$ & 0.13 & -0.80 & -0.29 & Negative and significant \\
\hline Distress $\leftarrow$ Body image $\leftarrow$ Surgery & $0.04^{*}$ & 0.01 & 0.03 & 0.05 & Positive and significant \\
\hline
\end{tabular}

The effect of undergoing or not undergoing surgery in the relationship between optimism and distress, indirect effect by body image

\begin{tabular}{|c|c|c|c|c|c|}
\hline Distress $\longleftarrow$ Body image $\longleftarrow$ Optimism & $0.33^{*}$ & 0.06 & 0.21 & 0.45 & Positive and significant \\
\hline $\begin{array}{l}\text { Distress } \longleftarrow \text { Body image } \longleftarrow \text { Surgery } \\
\times \text { Optimism }\end{array}$ & $-0.83^{*}$ & 0.17 & -1.16 & -0.51 & Negative and significant \\
\hline Distress $\leftarrow$ Body image $\leftarrow$ Surgery & $0.03^{*}$ & 0.01 & 0.02 & 0.04 & Positive and significant \\
\hline
\end{tabular}

The effect of undergoing or not undergoing surgery in the relationship between illness duration and distress, indirect effect by body image

\begin{tabular}{|c|c|c|c|c|c|}
\hline $\begin{array}{l}\text { Distress } \leftarrow \text { Body image } \leftarrow \text { Illness } \\
\text { duration }\end{array}$ & $0.12^{*}$ & 0.02 & 0.09 & 0.15 & Positive and significant \\
\hline $\begin{array}{l}\text { Distress } \longleftarrow \text { Body image } \leftarrow \text { Surgery } \\
\times \text { Illness duration }\end{array}$ & -0.05 & 0.09 & -0.24 & 0.12 & Not significant \\
\hline Distress $\leftarrow$ Body image $\leftarrow$ Surgery & $0.04^{*}$ & 0.01 & 0.03 & 0.05 & Positive and significant \\
\hline
\end{tabular}

\section{THE MODERATED INDIRECT EFFECT OF TYPE OF SURGERY}

For the adjusted model, a moderated indirect effect was tested regarding the two groups of surgery mastectomy versus conservative was tested and no significant results were found (Table 4).

\section{DISCUSSION}

The results showed that lower optimism and higher denial and illness duration predicted greater con- cerns with body image and higher distress. Other studies found similar results: women with great use of coping strategies, such as denial, were more likely to feel psychological distress (Di Mattei et al., 2016) and to experience more concerns with body image from surgery and/or alopecia from chemotherapy (Feudis et al., 2015). Women in the present study were all undergoing chemotherapy and about $70.1 \%$ were submitted to surgery, so it was expected that their body image perception would be compromised, impacting negatively on their psychological well-being. Although women with breast cancer are facing a life-threatening disease, body image plays a central
Role of body image in women with breast cancer 


\section{Figure 2}

Bayesian moderated indirect effect analysis: the effect of undergoing surgery or not in the relationship between denial, humor, optimism, illness duration and distress, through body image

M. Graça Pereira, Catarina Ribeiro, Gabriela Ferreira, José C. Machado, Ângela Leite
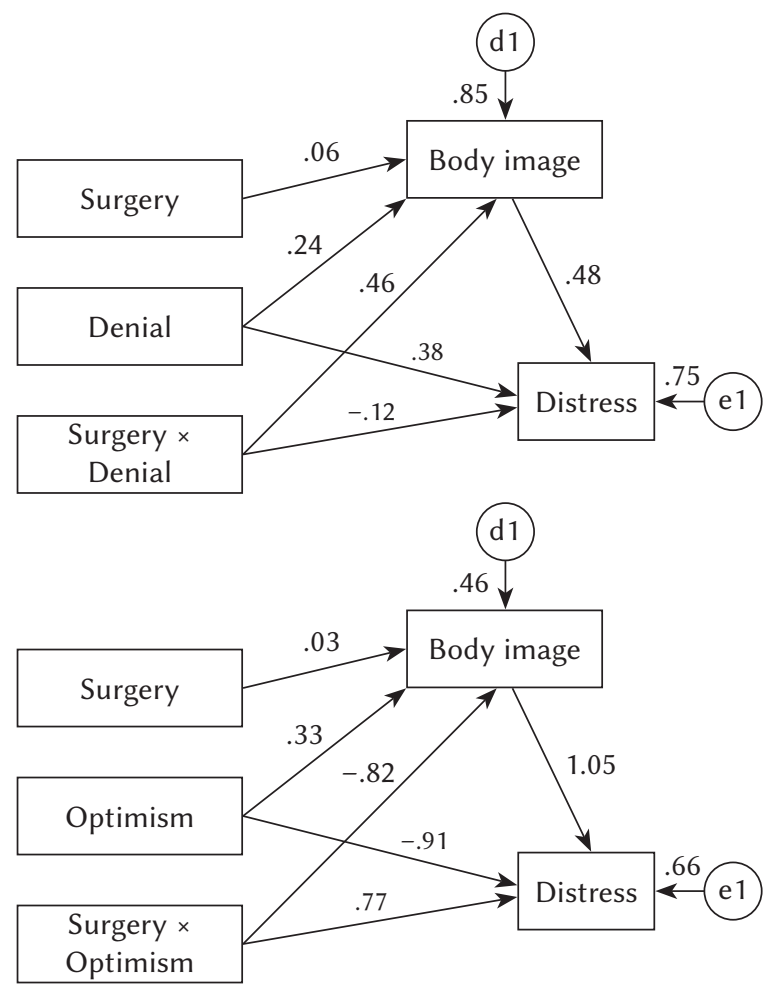

role for them, since the breast is considered a social symbol of femininity, sexuality, and motherhood and therefore, disfigurement may threaten women's emotional well-being and self-concept (Feudis et al., 2015). The present study found that concerns with body image had an indirect effect in the relationship between optimism and psychological distress. This relationship was also found in other studies (Carver, 2015) where being less optimistic about the future predicted concerns with body image since women face physical changes and related suffering.

The results also showed that longer illness duration predicted greater concerns with body image. However, a study found that longer illness duration was associated with lower body image distress (Helms et al., 2008). According to Stanton (2012), time by itself appears not to be a sufficient indicator of adaptation to breast cancer. Other studies, however, suggested that time may be a critical factor to predict disease adjustment (Brandt-Salmeri \& PrzybyłaBasista, 2019; Chow et al., 2015). There is still much controversy regarding the impact of time since diagnosis on the physical and psychological functioning of women diagnosed with breast cancer. Future studies should expand the knowledge on this issue using longitudinal designs.

The results showed that higher levels of optimism were associated with less use of denial coping, vent-
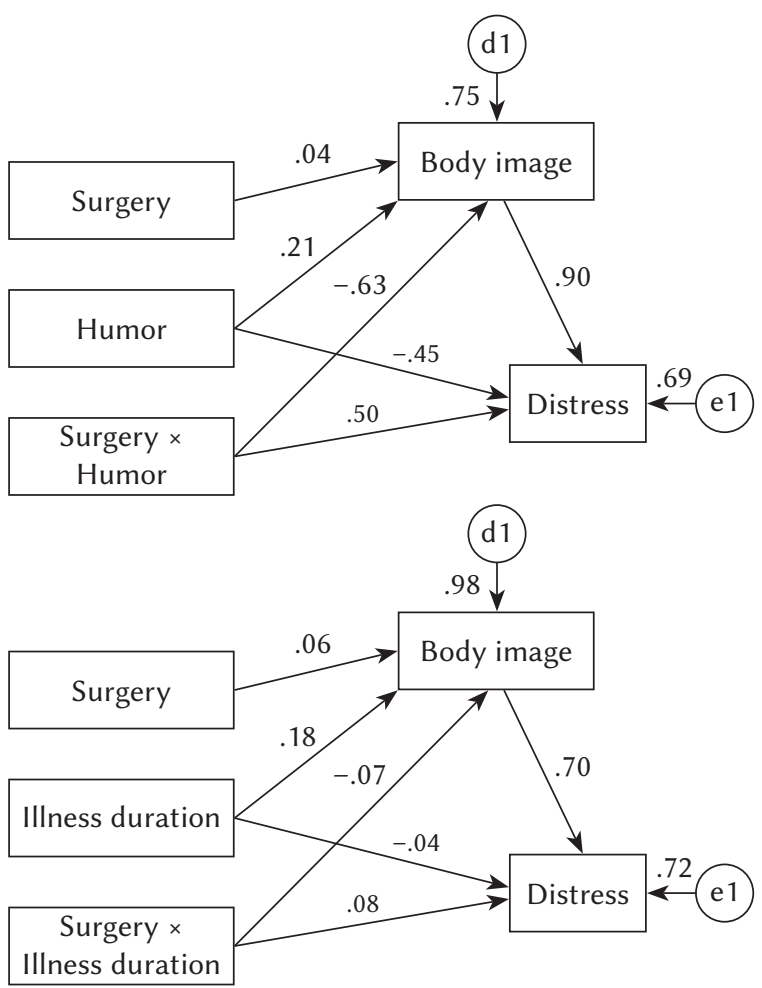

ing, and behavioral disengagement, as well as with greater use of positive reframing, acceptance, and humor. In fact, studies showed that optimism was associated with less use of avoidance coping strategies, such as denial and behavioral disengagement, as well as greater use of active coping strategies, such as acceptance, humor, and positive reframing, in cancer patients in general (WHO, 2019) and in women with breast cancer in particular, both before and after surgery (Carver, 2015). When facing a diagnosis of cancer, patients have reported adopting more often active-behavioral coping strategies than avoidance strategies (Ferlay et al., 2014; Brandão et al., 2016). However, another study found that avoidance strategies were not significantly associated with optimism, or with pessimism (Carver, 1997). Greater use of humor in turn was associated with distress. In fact, the present study corroborates results found in previous studies conducted in women with breast cancer, where a negative relationship between the use of humor and distress was found (Brunault et al., 2015). It is plausible that denial coping may act as an adaptive strategy to cope with overwhelming events and feelings (Di Mattei et al., 2016).

Although, several studies have suggested that more invasive surgery, such as mastectomy, when compared with breast conserving surgery, is more likely to contribute to body image problems and 
Table 4

Bayesian moderated indirect effect analysis: type of surgery

\begin{tabular}{|c|c|c|c|c|c|}
\hline $\begin{array}{l}\text { Path } \\
\text { Indirect effects }\end{array}$ & $\begin{array}{c}\text { Posterior } \\
M\end{array}$ & $S D$ & $\begin{array}{l}95 \% \\
\text { Lower } \\
\text { bound }\end{array}$ & $\begin{array}{l}95 \% \\
\text { Upper } \\
\text { bound }\end{array}$ & Conclusion \\
\hline
\end{tabular}

The effect of type of surgery in the relationship between denial and distress, indirect effect by body image

\begin{tabular}{llllll}
\hline Distress $\leftarrow$ Body image $\leftarrow$ Denial & $0.12^{*}$ & 0.03 & 0.07 & 0.17 & Positive and significant \\
Distress $\leftarrow$ Body image $\leftarrow$ Type & 0.02 & 0.07 & -0.11 & 0.15 & Not significant
\end{tabular}

of surgery $\times$ Denial

Distress $\leftarrow$ Body image $\leftarrow$ Type $\quad 0.03^{*} \quad 0.01 \quad 0.02 \quad 0.05 \quad$ Positive and significant of surgery

Note. Posterior predictive value is .50 ; number of samples for convergence is 13.81 ; DIC $=980.36$; $N=4673$; * statistically significant.

The effect of type of surgery in the relationship between humor and distress, indirect effect by body image

\begin{tabular}{llllll}
\hline Distress $\leftarrow$ Body image $\leftarrow$ Humor & $0.16^{*}$ & 0.02 & 0.12 & 0.21 & Positive and significant \\
Distress $\leftarrow$ Body image $\leftarrow$ Type & 0.03 & 0.09 & -0.15 & 0.22 & Not significant
\end{tabular}

of surgery $\times$ Humor

Distress $\leftarrow$ Body image $\leftarrow$ Type $\quad 0.04^{*} \quad 0.01 \quad 0.03 \quad 0.05 \quad$ Positive and significant of surgery

Note. Posterior predictive value is .50; number of samples for convergence is 13.65 ; DIC $=1,039.70 ; N=4643$; ${ }^{*}$ statistically significant.

The effect of type of surgery in the relationship between optimism and distress, indirect effect by body image

\begin{tabular}{lrrrrr}
\hline Distress $\leftarrow$ Body image $\leftarrow$ Optimism & $0.26^{*}$ & 0.05 & 0.15 & 0.23 & Positive and significant \\
Distress $\leftarrow$ Body image $\leftarrow$ Type & -0.07 & 0.08 & -0.24 & 0.08 & Not significant
\end{tabular}

of surgery $\times$ Optimism

Distress $\leftarrow$ Body image $\leftarrow$ Type $\quad 0.03^{*} \quad 0.01 \quad 0.01 \quad 0.04 \quad$ Positive and significant of surgery

Note. Posterior predictive value is .50; number of samples for convergence is 13.59 ; DIC $=1,218.31 ; N=4717$; statistically significant.

The effect of type of surgery in the relationship between illness duration and distress, indirect effect by body image

\begin{tabular}{lccccc}
\hline $\begin{array}{l}\text { Distress } \leftarrow \text { Body image } \leftarrow \text { Illness } \\
\text { duration }\end{array}$ & $0.11^{*}$ & 0.02 & 0.07 & 0.17 & Positive and significant \\
$\begin{array}{l}\text { Distress } \leftarrow \text { Body image } \leftarrow \text { Type } \\
\text { of surgery } \times \text { Illness duration }\end{array}$ & 0.10 & 0.07 & -0.04 & 0.25 & Not significant \\
$\begin{array}{l}\text { Distress } \leftarrow \text { Body image } \leftarrow \text { Type } \\
\text { of surgery }\end{array}$ & $0.04^{*}$ & 0.01 & 0.03 & 0.05 & Positive and significant \\
\begin{tabular}{l} 
Note. Posterior predictive value is $.50 ;$ number of samples for convergence is $13.55 ;$ DIC $=943.17 ; N=4717$; ${ }^{*}$ statistically significant. \\
\hline
\end{tabular}
\end{tabular}

decreased psychological well-being (Chow et al., 2015; Moreira et al., 2010), in this study, the type of surgery had no significant impact on the outcome. Also, the study by Fernandes et al. (2018) found no differences between mastectomized and non-mastectomized women. Contrary to type of surgery, it seems that being (or not) submitted to surgery had a more significant impact. Particularly, the positive relationship between distress and body image was significant only in the surgery group and not in the non-surgery group. Also, the indirect effect in the relationship between denial, humor coping and distress, through body image, was only present in the surgery group. In fact, the surgery itself, regardless of type, produced changes in the breast that interfere with women's body image that may increase distress (Helms et al., 2008). The use of emotion-focused coping strategies to deal with the distress makes intuitive sense at that moment of chemotherapy treatment, since the disease may be felt as uncontrollable (Brunault et al., 2015). Future studies should explore this result, in larger samples.
Role of body image in women with breast cancer 


\section{LIMITATIONS}

This study has some limitations that should be addressed, such as the cross-sectional design; the exclusive use of self-report measures and the small number of participants. Therefore, future studies should use longitudinal designs and bigger samples in order to analyze the mediator role of body image between coping strategies/optimism and distress as well as the moderator role of breast reconstruction over time, controlling

M. Graça Pereira, Catarina Ribeiro, Gabriela Ferreira, José C. Machado, Ângela Leite for other physical comorbidities besides breast cancer.

\section{IMPLICATIONS FOR PRACTICE}

This study suggests that health professionals should be aware of the importance of body image and psychological factors in women with breast cancer undergoing chemotherapy in order to intervene to promote adaptive coping strategies and optimism. When women struggle with distress and body image issues, a referral for psychological support may be needed, particularly in women who have undergone surgery, regardless of the type.

\section{CONCLUSIONS}

This study highlights the importance of concerns with body image since it showed an indirect effect in the relationship between illness duration, optimism, denial/humor coping and psychological distress. Thus, future interventions, for women with breast cancer, should consider body image as a target, in order to promote adaptive coping strategies, and higher levels of optimism, which will allow patients to cope with the stressors associated with breast cancer during chemotherapy.

\section{References}

Al-Ghazal, S., Fallowfield, L., \& Blamey, R. (2000). Comparison of psychological aspects and patient satisfaction following breast conserving surgery, simple mastectomy and breast reconstruction. European Journal of Cancer, 36, 1938-1943. https:// doi.org/10.1016/s0959-8049(00)00197-0

American Cancer Society (2019). Breast cancer facts \& figures. Retrieved from https://www.cancer.org/ research/cancer-facts-statistics/breast-cancerfacts-figures.html [accessed June 4, 2019]

Brandão, T., Schulz, M. S., \& Matos, P. M. (2016). Psychological adjustment after breast cancer: a systematic review of longitudinal studies. Psycho-Oncology, 26, 917-926. https://doi.org/10.1002/pon.4230.

Brandt-Salmeri, A., \& Przybyła-Basista, H. (2019). Body image and self-esteem in women with breast can- cer - the role of body acceptance. Psychoonkologia, 22, 1-10. https://doi.org/10.5114/pson.2018.81160

Brunault, P., Champagne, A. L., Huguet, G., Suzanne, I., Senon, J. L., Body, G., Rusch, E., Magnin, G., Voyer, M., Réveillère, C., \& Camus, V. (2015). Major depressive disorder, personality disorders, and coping strategies are independent risk factors for lower quality of life in non-metastatic breast cancer patients. Psycho-Oncology, 25, 513-520. https://doi. org/10.1002/pon.3947

Carver, C. S. (1997). You want to measure coping but your protocol' too long: Consider the brief cope. International Journal of Behavioral Medicine, 4, 92100. https://doi.org/10.1207/s15327558ijbm0401_6

Carver, C. S. (2015). Optimism and pessimism. In J. D. Wright (Ed.), International encyclopedia of the social \& behavioral sciences (2nd ed.) (pp. 263-267). Elsevier.

Casellas-Grau, A., Vives, J., Font, A., \& Ochoa, C. (2016). Positive psychological functioning in breast cancer: an integrative review. The Breast, 27, 136168. https://doi.org/10.1016/j.breast.2016.04.001

Chow, R., Pulenzas, N., Zhang, L., Ecclestone, C., Leahey, A., Hamer, J., DeAngelis, C., Bedard, G., McDonald, R., Bhatia, A., Ellis, J., Rakovitch, E., Vuong, S., Chow, E., \& Verma, S. (2015). Quality of life and symptom burden in patients with breast cancer treated with mastectomy and lumpectomy. Supportive Care in Cancer, 24, 2191-2199. https:// doi.org/10.1007/s00520-015-3027-8

Di Mattei, V., Bernardi, M., Madeddu, F., \& Sarno, L. (2016). Psychological distress and coping strategies among women who undergo cancer genetic testing. In C. Pracana (Ed.), Psychology applications and developments II (pp. 15-24). Science Press.

Dua, P., Heiland, M. F., Kracen, A. C., \& Deshields, T. L. (2015). Cancer-related hair loss: a selective review of the alopecia research literature. Psycho-Oncology, 26, 438-443. https://doi.org/10.1002/pon.4039.

Fang, S. Y., Chang, H. T., \& Shu, B. C. (2014). Objectified body consciousness, body image discomfort, and depressive symptoms among breast cancer survivors in Taiwan. Psychology of Women Quarterly, 38, 563-574. https://doi.org/10.1177/0361684314552652

Ferlay, J., Soerjomataram, I., Dikshit, R., Eser, S., Mathers, C., Rebelo, M., Parkin, D. M., Forman, D., \& Bray, B. (2014). Cancer incidence and mortality worldwide: Sources, methods and major patterns in GLOBOCAN 2012. International Journal of Cancer, 136, E359-E386. https://doi.org/10.1002/ijc.29210

Fernandes, S., McIntyre, T., \& Leite, Â. (2018). Ajustamento psicossocial ao cancro da mama em função do tipo de cirurgia [Psychosocial adjustment to breast cancer according to the type of surgery]. Análise Psicológica, 36, 199-217. https://doi. org/10.15309/16psd170208

Feudis, R. D., Lanciano, T., \& Rinaldi, S. (2015). Coping strategies of southern Italian women predict 
distress following breast cancer surgery. Europe's Journal of Psychology, 11, 280-294. https://doi. org/10.5964/ejop.v11i2.908

Griffiths, S., Hay, P., Mitchison, D., Mond, J. M., Mclean, S. A., Rodgers, B., Massey, R., \& Paxton, S. J. (2016). Sex differences in the relationships between body dissatisfaction, quality of life and psychological distress. Australian and New Zealand Journal of Public Health, 40, 518-522. https://doi.org/10.1111/1753-6405.12538

van de Grift, T. C., Cohen-Kettenis, P.T., deVries, A. L. C., \& Kreukels, B. P. C. (2018). Body image and selfesteem in disorders of sex development: a European multicenter study. Health Psychology, 37, 334-343. https://doi.org/10.1037/hea0000600

Helms, R. L., Ohea, E. L., \& Corso, M. (2008). Body image issues in women with breast cancer. Psychology, Health \& Medicine, 13, 313-325. https:// doi.org/10.1080/13548500701405509

Hopwood, P., \& Hopwood, N. (2019). New challenges in psycho-oncology: an embodied approach to body image. Psycho-Oncology, 28, 211-218. https:// doi.org/10.1002/pon.4936

Hopwood, P., Fletcher, I., Lee, A., \& Ghazal, S. A. (2001). A body image scale for use with cancer patients. European Journal of Cancer, 37, 189-197. https://doi.org/10.1016/s0959-8049(00)00353-1

Kowalczyk, R., Nowosielski, K., Cedrych, I., Krzystanek, M., Glogowska, I., Streb, J., Kucharz, J., \& Lew-Starowicz, Z. (2019). Factors affecting sexual function and body image of early-stage breast cancer survivors in Poland: a short-term observation. Clinical Breast Cancer, 19, e30-e39. https:// doi.org/10.1016/j.clbc.2018.09.006

Laranjeira, C. A. (2008). Tradução e validação portuguesa do revised life orientation test (LOT-R) [Portuguese translation and validation of the $\mathrm{Re}$ vised Life Orientation Test (LOT-R)]. Universitas Psychologica, 7, 469-476.

Li, Y., Qiao, Y., Luan, X., Li, S., \& Wang, K. (2019). Family resilience and psychological well-being among Chinese breast cancer survivors and their caregivers. European Journal of Cancer Care, 28, e12984. https://doi.org/10.1111/ecc. 12984

Millar, K., Purushotham, A. D., Mclatchie, E., George, W. D., \& Murray, G. D. (2005). A 1-year prospective study of individual variation in distress, and illness perceptions, after treatment for breast cancer. Journal of Psychosomatic Research, 58, 335342. https://doi.org/10.1016/j.jpsychores.2004.10.005

Moreira, H., Silva, S., Marques, A., \& Canavarro, M. C. (2010). The Portuguese version of the Body Image Scale (BIS) - psychometric properties in a sample of breast cancer patients. European Journal of Oncology Nursing, 14, 111-118. https://doi.org/10.1016/j. ejon.2009.09.007

Pais-Ribeiro, J., Silva, I., Ferreira, T., Martins, A., Meneses, R., \& Baltar, M. (2007). Validation study of a Portuguese version of the Hospital Anxiety and Depression Scale. Psychology, Health \& Medicine, 12, 225-237. https://doi.org/10.1080/13548500500524088 Reich, M., Lesur, A., \& Perdrizet-Chevallier, C. (2007). Depression, quality of life and breast cancer: a review of the literature. Breast Cancer Research and Treatment, 110, 9-17. https://doi.org/10.1007/s10549-007-9706-5

Ribeiro, J., \& Rodrigues, A. (2004). Questões acerca do coping: a propósito do estudo de adaptação do Brief COPE [Some questions about coping: The study of the Portuguese adaptation of the Brief COPE]. Psicologia, Saúde \& Doenças, 5, 3-15.

Ristevska-Dimitrovska, G., Filov, I., Rajchanovska, D., Stefanovski, P., \& Dejanova, B. (2015). Resilience and quality of life in breast cancer patients. Open Access Macedonian Journal of Medical Sciences, 3, 727-731. https://doi.org/10.3889/oamjms.2015.128

Rogers, C. B., Webb, J. B., \& Jafari, N. (2018). A systematic review of the roles of body image flexibility as correlate, moderator, mediator, and in intervention science (2011-2018). Body Image, 27, 43-60. https://doi.org/10.1016/j.bodyim.2018.08.003

Scheier, M. F., Carver, C. S., \& Bridges, M. W. (1994). Distinguishing optimism from neuroticism (and trait anxiety, self-mastery, and self-esteem): a reevaluation of the Life Orientation Test. Journal of Personality and Social Psychology, 67, 1063-1078. https://doi.org/10.1037//0022-3514.67.6.1063

Song, X. Y., \& Lee, S. Y. (2006). Bayesian analysis of structural equation models with nonlinear covariates and latent variables. Multivariate Behavioral Research, 41, 337-365. https://doi.org/10.1207/s15327906mbr4103_4

Stanton, A. L. (2012). What happens now? Psychosocial care for cancer survivors after medical treatment completion. Journal of Clinical Oncology, 30, 12151220. https://doi.org/10.1200/JCO.2011.39.7406

Teo, I., Novy, D. M., Chang, D. W., Cox, M. G., \& Fingeret, M. C. (2015). Examining pain, body image, and depressive symptoms in patients with lymphedema secondary to breast cancer. Psycho-Oncology, 24, 1377-1383. https://doi.org/10.1002/pon.3745 van de Schoot, R., \& Depaoli, S. (2014). Bayesian analyses: Where to start and what to report. The European Health Psychologist, 16, 75-84.

World Health Organization (2019). Cancer. Retrieved from https://www.who.int/en/news-room/factsheets/detail/cancer [accessed June 4, 2019]

You, S., Shin, K., \& Kim, A. Y. (2016). Body image, selfesteem, and depression in Korean adolescents. Child Indicators Research, 10, 231-245. https://doi. org/10.1007/s12187-016-9385-Z

Yuan, Y., \& Mackinnon, D. P. (2009). Bayesian mediation analysis. Psychological Methods, 14, 301-322. https://doi.org/10.1037/a0016972

Zigmond, A. S., \& Snaith, R. P. (1983). Hospital Anxiety and Depression Scale. Acta Psychiatrica Scandinavica, 67, 361-370. https://doi.org/10.1111/j. 1600-0447.1983.tb09716.x
Role of body image in women with breast cancer 